Taku Yoneyama $\cdot$ Hidetoshi Kasuya $\cdot$ Hideaki Onda

Hiroyuki Akagawa $\cdot$ Nobuyoshi Jinnai

Toshiaki Nakajima · Tomokatsu Hori · Ituro Inoue

\title{
Association of positional and functional candidate genes FGF1, FBN2, and LOX on 5q31 with intracranial aneurysm
}

Received: 7 March 2003/ Accepted: 4 April 2003/Published online: 16 May 2003

(C) The Japan Society of Human Genetics and Springer-Verlag 2003

\begin{abstract}
We previously performed a genome-wide linkage study of intracranial aneurysm (IA) and found positive evidence of linkage at chromosomes 5q22-31, $7 \mathrm{q} 11$, and $14 \mathrm{q} 22$. In the present study, we focus on $5 \mathrm{q} 31$, where three candidate genes, fibroblast growth factor 1 $(F G F 1)$, fibrillin 2 (FBN2), and lysyl oxidase gene $(L O X)$ lie, and evaluate associations with IA. Genomic DNAs were obtained from 172 IA patients and 192 controls. Association analysis was performed with ten, five, and four single-nucleotide polymorphisms (SNPs) identified in $F G F 1, F B N 2$, and $L O X$, respectively. A difference in allelic frequency was observed for only the SNP at intron 4 in FGF1 $\left(\chi^{2}=4.44\right.$, $\left.\mathrm{df}=1, P=0.035\right)$. Although a haplotype association was observed with the combination of ten SNPs in FGF1 $\left(\chi^{2}=16.04\right.$, df $=1$, $P=0.00006)$, significant haplotype associations were not observed when haplotypes were constructed with the three, two, and four SNPs in FGF1 according to the linkage disequilibrium structure. No associations of $F B N 2$ and $L O X$ with IA were detected in the present study.
\end{abstract}

Keywords Intracranial aneurysm - Haplotype analysis $\cdot$ Linkage disequilibrium $\cdot F G F 1 \cdot F B N 2 \cdot L O X$

T. Yoneyama $\cdot$ H. Kasuya $\cdot$ H. Onda $\cdot$ H. Akagawa $\cdot$ T. Hori Department of Neurosurgery, Neurological Institute, Tokyo

Women's Medical University, Tokyo, Japan

N. Jinnai

Theranostics Research Center, Otsuka Pharmaceutical Company, Tokushima, Japan

T. Yoneyama $\cdot$ H. Akagawa $\cdot$ N. Jinnai

T. Nakajima $\cdot$ I. Inoue $(\bowtie)$

Division of Genetic Diagnosis, The Institute of Medical Science,

The University of Tokyo, 4-6-1 Shirokanedai, Minato-ku,

Tokyo 108-8639, Japan

E-mail: ituro@ims.u-tokyo.ac.jp

Tel.: + 81-3-54495325

Fax: $+81-3-54495764$

\section{Introduction}

The genetic factors of complex diseases are increasingly being recognized as pivotal in their etiology. Subarachnoid hemorrhage (SAH) resulting from the rupture of an intracranial aneurysm (IA) has high morbidity and mortality and constitutes a major public health problem. Despite improvements in medical and neurosurgical treatment over the past several decades, the prognosis for aneurysmal SAH has changed little from 40 years ago (Ingall et al. 1989; Fogelholm et al. 1993; Inagawa et al. 1995). The risk of ruptured IA in first-degree relatives of patients with aneurysmal SAH is four times higher and the relative risk in siblings is six times higher than that in the general population, so that genetic causes of IA have been considered (Schievink et al. 1995; Ronkainen et al. 1997). We have previously reported a genome-wide linkage study of IA with 104 Japanese affected sib pairs in which positive evidence of linkage on chromosomes 5q22-31, 7q11, and $14 \mathrm{q} 22$ has been observed (Onda et al. 2001). The best evidence of linkage was found on chromosome 7q11, and possible involvement of the elastin gene in the pathogenesis of IA was suggested. However, because of the nature of IA, other genetic loci might well be involved in the pathogenesis. We have focused on chromosome 5q31, where evidence of linkage (maximum lod score $=2.24$ ) has been detected, and where three candidate genes, fibroblast growth factor 1 $(F G F 1)$, fibrillin 2 (FBN2), and lysyl oxidase ( $L O X)$, lie within 1-lod support interval (suggestive linkage region).

Fibroblast growth factor-1, encoded by $F G F 1$, is a potent angiogenetic factor that induces capillary formation and vascular smooth muscle cell proliferation and migration in cell cultures, together with fibroblast growth factor-2 (Baird et al. 1986; Gospodarowicz et al. 1986; Klagsbrun and D'Amore 1991). Recombinant fibroblast growth factor-1 promotes intimal hyperplasia and angiogenesis in porcine arteries in vivo (Nabel et al. 
1993). FBN2 is responsible for congenital contractural arachnodactyly, which shares some of the physical features of Marfan syndrome caused by FBN1 mutation (Tsipouras et al. 1992). Fibrillin 1 and 2 are large cystein-rich glycoproteins that form microfibrils and that play a central role in elastic fibrogenesis (Kielty and Shuttleworth 1995; Robinson and Godfrey 2000). Lysyl oxidase, encoded by $L O X$, is an extracellular copper enzyme that initiates cross-linking processes by catalyzing oxidative deamination of epsilon-amino groups in certain lysine or hydroxylysine residues of collagens and lysine residues of elastin (Kagan et al. 1986; Kagan and Trackman 1991). Therefore, oxidation of lysyl residues should enhance the strength of blood vessel walls. These three positional and functional candidate genes for IA on chromosome $5 \mathrm{q} 31$ were analyzed for allelic and haplotype associations, and their possible involvements in the etiology of IA are evaluated.

\section{Subjects and methods}

\section{Subjects}

The Ethical Committee of Tokyo Women's Medical University approved the study, and all the participants gave written informed consent. The DNA samples for association study were from 172 IA patients and 192 controls. The IA patients included 78 IA probands in nuclear families, nine patients with first-degree relatives with IA, and 85 patients with no known family history of IA (IA group: 70 men and 102 women; mean age $\pm \mathrm{SD}, 59.8 \pm 10.5$ years). The presence of IA was confirmed by surgical findings, conventional angiography, three-dimensional computerized tomographic angiography, or magnetic resonance angiography. The 192 unrelated controls were outpatients in the Department of Neurosurgery, Neurological Institute, Tokyo Women's Medical University, with diseases other than IA, such as headache (control group: 91 men and 101 women: mean age $\pm \mathrm{SD}, 59.0 \pm 16.5$ years). All subjects were of Japanese ethnicity.

Genotyping and single-nucleotide polymorphisms of FGF1, FBN2, and $L O X$

Genomic DNA was extracted from peripheral blood according to a standard method. IA patients $(n=24)$ were screened to identify single-nucleotide polymorphisms (SNPs) in FGF1, FBN2, and $L O X$. Direct sequencing was performed on polymerase chain reaction (PCR)-amplified segments spanning exons, acceptor, donor, and branch-point sequences of introns, the putative promoter sequence (approximately $1 \mathrm{~kb}$ ), and the 3'UTR sequence. Additionally, SNPs in the NCBI database (http:// www.ncbi.nlm.nih.gov/SNP/) were obtained (rs32209, rs154001, rs 190450 , rs764368, and rs989548 were used). All primer sets were designed on genomic sequences obtained through the GenBank database (accession numbers: GI:15295971, FGF1; GI:15295011, FBN2; GI:14722561, LOX), and each segment of FGF1, FBN2, and $L O X$ was amplified with a Gene Amp PCR systems 9700 (Applied Biosystems, Tokyo, Japan) by using $10 \mathrm{ng}$ genomic DNA derived from each of the samples. Initial denaturation was at $95^{\circ} \mathrm{C}$ for $1 \mathrm{~min}$, followed by 35 amplification cycles of denaturation at $94^{\circ} \mathrm{C}$ for $30 \mathrm{~s}$, annealing at $58-64^{\circ} \mathrm{C}$ for $30 \mathrm{~s}$, and extension at $72^{\circ} \mathrm{C}$ for $0.5-1 \mathrm{~min}$. Annealing temperatures and extension durations were adjusted according to the melting temperature of each pair of primers.

\section{Statistical analysis}

Allelic association with IA was evaluated by the chi-square test for each SNP between cases and controls. The haplotype frequencies with phase-unknown samples and linkage disequilibrium (LD) between all pairs of SNPs in $F G F 1, F B N 2$, and $L O X$ were calculated by using the SNPAlyse program (DYNACOM, Yokohama, Japan, http://www.dynacom.co.jp/). LD was estimated as $D=$ $x_{i j}-p_{i} p_{j}$, where $x_{i j}$ is the frequency of haplotype $\mathrm{A}_{1} \mathrm{~B}_{1}$, and $p_{1}$ and $p_{2}$ are the frequencies of alleles $\mathrm{A}$ and $\mathrm{B}$, respectively. A standard LD coefficient, $r$, is given by $D /\left(p_{1} p_{2} q_{1} q_{2}\right)^{1 / 2}$, where $q_{1}$ and $q_{2}$ are the frequencies of the other alleles at loci $\mathrm{A}$ and $\mathrm{B}$, respectively (Hill and Robertson 1968). Lewontin's coefficient, $D^{\prime}$, is given by $D^{\prime}=D /$ $D_{\max }$, where $D_{\max }=\min \left(p_{1} p_{2}, q_{1} q_{2}\right)$, when $D<0$, or $D_{\max }=$ $\min \left(q_{1} p_{2}, p_{1} q_{2}\right)$, when $D>0$ (Lewontin 1964). The haplotype frequencies of three genes were compared between IA patients and controls and evaluated by contingency tables of the chi-square test.

\section{Results}

The subjects in the current association study are presented in Table 1. Familial IA was defined as occurring in patients who have first-degree relatives diagnosed as having IA. There was no significant differences in age between IA patients and controls; however, female dominance in familial IA patients was observed.

The candidate genes on chromosome $5 \mathrm{q} 31$ where evidence of linkage (maximum lod score $=2.24$ ) has previously been reported (Onda et al. 2001) are FGF1, $F B N 2$, and $L O X$, lying $4.9,9.7$, and $15.9 \mathrm{Mb}$ apart from a peak linkage marker, D5S1983, respectively. The relative positions of these genes and the markers in the linkage region are depicted in Fig. 1. Systematic direct sequencing was performed on the genes, and ten, five, and four distinct SNPs were identified. The exon-intron organizations of the genes and the SNP positions are depicted in Fig. 1. No SNP in FGF1 showed an amino acid substitution, whereas one SNP in FBN2 and two in $L O X$ showed substitutions (Table 2). The allelic frequencies of all of the SNPs identified were compared between the IA patients and controls and evaluated by the chi-square test (Table 2). Among the SNPs analyzed, only one SNP in $F G F 1$ reached weak statistical significance $\left(\chi^{2}=4.44, \mathrm{df}=1, P=0.035\right.$ for FG8 at intron 4$)$.

Haplotypes were constructed on the basis of the genotype data from SNPs within the three genes, and the haplotype associations were examined. In FGF1, a haplotype constructed with all ten SNPs was observed more frequently in IA patients than in controls, with significant difference $\left(\chi^{2}=16.04, \quad \mathrm{df}=1, \quad P=0.00006\right.$; Table 3). No significant association between haplotypes

Table 1 Samples for case-control study ( $I A$ intracranial aneurysm)

\begin{tabular}{lll}
\hline Group & Number (male/female) & Mean age \pm SD \\
\hline IA (total) & $172(70 / 102)$ & $59.8 \pm 10.5$ \\
Familial IA & $87(27 / 60)$ & $60.7 \pm 9.7$ \\
Sporadic IA & $85(43 / 42)$ & $58.9 \pm 11.1$ \\
Control & $192(91 / 101)$ & $59.0 \pm 16.5$ \\
\hline
\end{tabular}




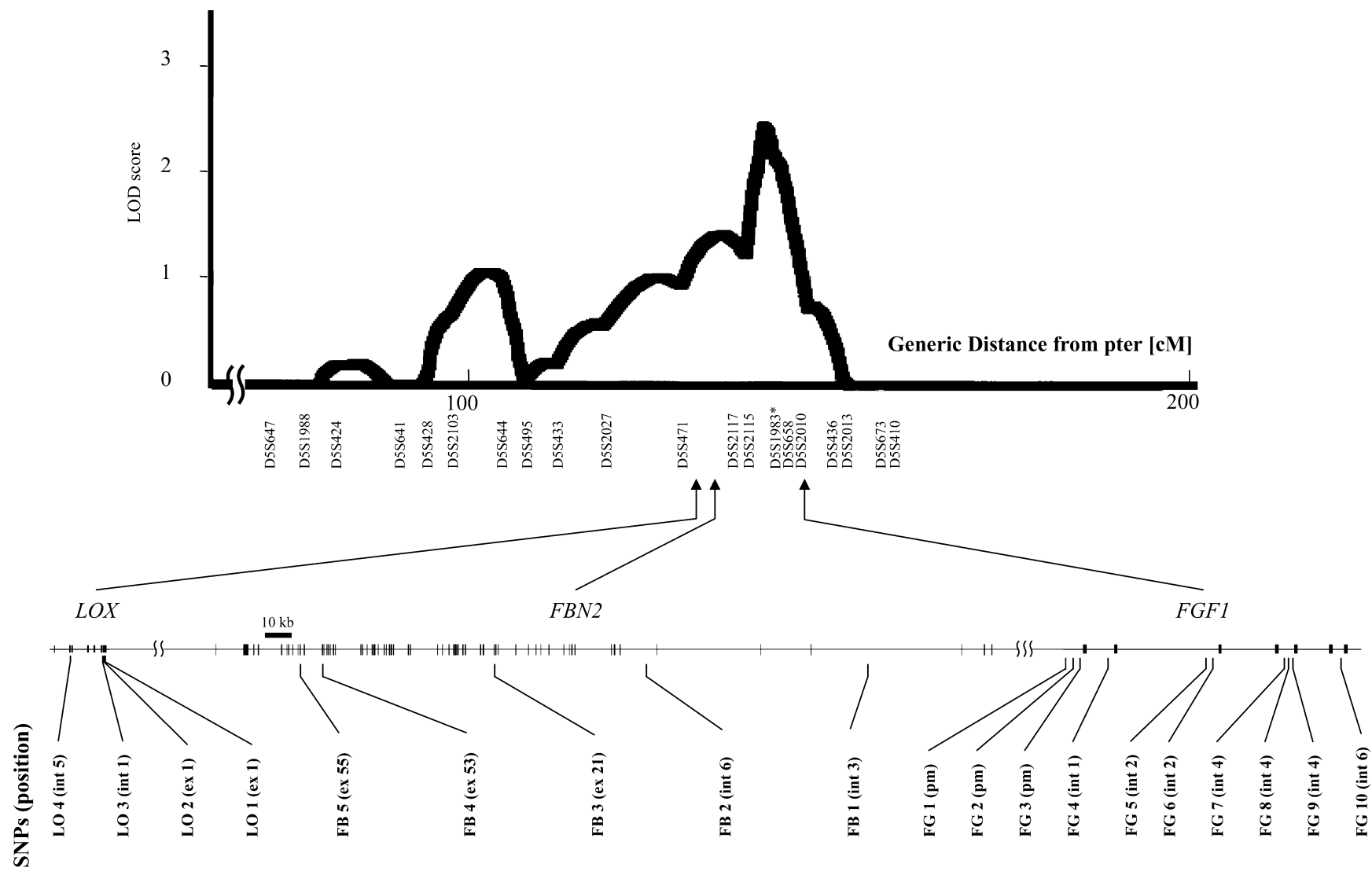

Fig. 1 Location of $F G F 1, F B N 2$, and $L O X$ in the linkage region on chromosome 5q31. Top Results of multipoint linkage analysis on chromosome 5 with 104 Japanese sib pairs for IA. The linkage peak is near marker D5S1983 (asterisk), with a distance from the pterminal end (pter) of $141.4 \mathrm{cM}$. Bottom Location and organization of $F G F 1, F B N 2$, and $L O X$. The SNPs analyzed in the present study are marked and IA was found in the combinations of the five SNPs in FBN2 and the four SNPs in $L O X$ (Tables 4, 5).

Patterns of linkage disequilibrium in the three genes were illustrated by their $\left|D^{\prime}\right|$ and $r^{2}$ values (Fig. 2). In $F G F 1$, two LD blocks, defined by having $\left|D^{\prime}\right|>0.5$, were observed. All SNPs of FBN2 and $L O X$ were in tight LD
Table 2 Polymorphisms in $F G F 1, F B N 2$, and $L O X$, and association study of patients with IA and controls (position number of nucleotides from the first nucleotide (A) of the start codon, $M$ major allele, $m$ minor allele)

\begin{tabular}{|c|c|c|c|c|c|c|c|}
\hline \multirow{2}{*}{$\begin{array}{l}\text { SNP } \\
\text { name }\end{array}$} & \multirow{2}{*}{$\begin{array}{l}\text { Location } \\
\text { (position) }\end{array}$} & \multicolumn{2}{|c|}{ Variation } & \multicolumn{2}{|l|}{ Allele frequency } & \multirow[b]{2}{*}{$\chi^{2}$} & \multirow[b]{2}{*}{$P(\mathrm{df}=1)$} \\
\hline & & $\mathrm{M} \rightarrow \mathrm{m}$ & Amino acid & Control & IA & & \\
\hline \multicolumn{8}{|l|}{$F G F 1$} \\
\hline FG 1 & Promoter $(-84158)$ & $\mathrm{A} \rightarrow \mathrm{G}$ & & $0.394(149 / 378)$ & $0.417(131 / 314)$ & 0.337 & 0.539 \\
\hline FG 2 & Promoter $(-84010)$ & $\mathrm{T} \rightarrow \mathrm{C}$ & & $0.263(99 / 376)$ & $0.273(84 / 308)$ & 0.077 & 0.782 \\
\hline FG 3 & Promoter $(-84007)$ & $\mathrm{G} \rightarrow \mathrm{A}$ & & $0.128(48 / 376)$ & $0.136(42 / 308)$ & 0.112 & 0.738 \\
\hline FG 4 & Intron $1(-72529)$ & $\mathrm{C} \rightarrow \mathrm{T}$ & & $0.191(66 / 346)$ & $0.178(58 / 326)$ & 0.184 & 0.668 \\
\hline FG 5 & Intron $2(-30551)$ & $\mathrm{A} \rightarrow \mathrm{G}$ & & $0.479(180 / 376)$ & $0.450(145 / 322)$ & 0.563 & 0.453 \\
\hline FG 6 & Intron $2(-30390)$ & $\mathrm{C} \rightarrow \mathrm{G}$ & & $0.097(37 / 380)$ & $0.107(35 / 326)$ & 0.191 & 0.662 \\
\hline FG 7 & Intron $4(-2085)$ & $\mathrm{T} \rightarrow \mathrm{C}$ & & $0.426(155 / 364)$ & $0.451(146 / 324)$ & 0.428 & 0.513 \\
\hline FG 8 & Intron $4(-1933)$ & $\mathrm{A} \rightarrow \mathrm{G}$ & & $0.058(21 / 360)$ & $0.102(33 / 324)$ & 4.441 & 0.035 \\
\hline FG 9 & Intron $4(-175)$ & $\mathrm{G} \rightarrow \mathrm{A}$ & & $0.151(52 / 344)$ & $0.153(49 / 320)$ & 0.005 & 0.944 \\
\hline FG10 & Intron 6 (18623) & $\mathrm{G} \rightarrow \mathrm{T}$ & & $0.329(123 / 374)$ & $0.370(119 / 322)$ & 1.263 & 0.261 \\
\hline \multicolumn{8}{|c|}{$F B N 2$} \\
\hline FB 1 & Intron $3(-97407)$ & $\mathrm{T} \rightarrow \mathrm{G}$ & & $0.249(94 / 378)$ & $0.268(91 / 340)$ & 0.337 & 0.562 \\
\hline FB 2 & Intron $6(-11340)$ & $\mathrm{A} \rightarrow \mathrm{C}$ & & $0.018(7 / 380)$ & $0.038(13 / 340)$ & 2.609 & 0.106 \\
\hline FB 3 & Exon $21(+43917)$ & $\mathrm{A} \rightarrow \mathrm{G}$ & Val $\rightarrow$ Ile & $0.092(35 / 380)$ & $0.094(32 / 342)$ & 0.005 & 0.946 \\
\hline FB 4 & Exon $53(+106552)$ & $\mathrm{G} \rightarrow \mathrm{A}$ & UTR & $0.389(148 / 380)$ & $0.397(135 / 340)$ & 0.043 & 0.835 \\
\hline FB 5 & Exon $55(+114575)$ & $\mathrm{C} \rightarrow \mathrm{T}$ & UTR & $0.132(50 / 380)$ & $0.093(32 / 344)$ & 2.672 & 0.102 \\
\hline \multicolumn{8}{|l|}{$L O X$} \\
\hline LO 1 & Exon $1(+225)$ & $\mathrm{C} \rightarrow \mathrm{G}$ & Ala $\rightarrow$ Ala & $0.061(23 / 380)$ & $0.058(20 / 342)$ & 0.013 & 0.908 \\
\hline LO 2 & Exon $1(+473)$ & $\mathrm{G} \rightarrow \mathrm{A}$ & Arg $\rightarrow$ Gln & $0.184(70 / 380)$ & $0.162(53 / 328)$ & 0.628 & 0.428 \\
\hline LO 3 & Intron $1(+791)$ & $\mathrm{G} \rightarrow \mathrm{C}$ & & $0.120(45 / 374)$ & $0.096(32 / 334)$ & 1.094 & 0.296 \\
\hline LO 4 & Intron $5(+7692)$ & $\mathrm{C} \rightarrow \mathrm{A}$ & & $0.077(28 / 362)$ & $0.059(19 / 324)$ & 0.937 & 0.333 \\
\hline
\end{tabular}


Table 3 Estimated haplotype frequencies calculated from SNPs in FGF1 ( $M$ major allele, $m$ minor allele)

\begin{tabular}{|c|c|c|c|c|c|c|c|c|c|c|c|c|c|c|}
\hline \multirow[t]{2}{*}{ No. } & \multicolumn{10}{|c|}{ SNP name } & \multicolumn{2}{|c|}{ Frequency } & \multirow[b]{2}{*}{$\chi^{2}$} & \multirow[b]{2}{*}{$P(\mathrm{df}=1)$} \\
\hline & FG1 & FG2 & FG3 & FG4 & FG5 & FG6 & FG7 & FG8 & FG9 & FG10 & Control & IA & & \\
\hline 1 & M & M & M & M & $\mathrm{m}$ & M & M & M & M & $\mathrm{m}$ & 0.023 & 0.103 & 16.036 & 0.000062 \\
\hline 2 & $\mathrm{M}$ & $\mathrm{M}$ & M & $\mathrm{M}$ & $\mathrm{M}$ & M & $\mathrm{m}$ & $\mathrm{M}$ & $\mathrm{M}$ & M & 0.103 & 0.090 & 0.326 & 0.568 \\
\hline 3 & M & M & M & M & M & M & M & M & M & $\mathrm{m}$ & 0.079 & 0.070 & 0.309 & 0.578 \\
\hline 4 & M & $\mathrm{M}$ & M & M & $\mathrm{m}$ & M & $\mathrm{m}$ & M & $\mathrm{M}$ & M & 0.138 & 0.057 & 10.331 & 0.0013 \\
\hline 5 & M & M & M & & & & & & & & 0.600 & 0.596 & 0.009 & 0.923 \\
\hline 6 & $\mathrm{~m}$ & $\mathrm{~m}$ & M & & & & & & & & 0.250 & 0.256 & 0.038 & 0.846 \\
\hline 7 & $\mathrm{~m}$ & M & $\mathrm{m}$ & & & & & & & & 0.128 & 0.132 & 0.045 & 0.833 \\
\hline 8 & & & & & $\mathrm{~m}$ & M & & & & & 0.473 & 0.467 & 0.040 & 0.842 \\
\hline 9 & & & & & M & M & & & & & 0.427 & 0.420 & 0.057 & 0.812 \\
\hline 10 & & & & & M & $\mathrm{m}$ & & & & & 0.099 & 0.112 & 0.332 & 0.564 \\
\hline 11 & & & & & & & M & M & M & $\mathrm{m}$ & 0.327 & 0.359 & 0.686 & 0.407 \\
\hline 12 & & & & & & & $\mathrm{~m}$ & M & M & M & 0.365 & 0.332 & 0.705 & 0.401 \\
\hline 13 & & & & & & & $\mathrm{M}$ & M & M & M & 0.148 & 0.145 & 0.015 & 0.904 \\
\hline 14 & & & & & & & $\mathrm{~m}$ & $\mathrm{~m}$ & $\mathrm{~m}$ & M & 0.057 & 0.100 & 3.496 & 0.062 \\
\hline 15 & & & & & & & M & $\mathrm{M}$ & $\mathrm{m}$ & M & 0.095 & 0.050 & 4.961 & 0.026 \\
\hline
\end{tabular}

showing one LD block. SNPs in LD were selected according to the LD structure of $F G F 1$, and then the haplotype was constructed as shown in Table 3. When

Table 4 Estimated haplotype frequencies calculated from SNPs in $F B N 2$ ( $M$ major allele, $m$ minor allele)

\begin{tabular}{|c|c|c|c|c|c|c|c|c|c|}
\hline \multirow[t]{2}{*}{ No. } & \multicolumn{5}{|c|}{ SNP name } & \multicolumn{2}{|c|}{ Frequency } & \multirow[b]{2}{*}{$\chi^{2}$} & \multirow[b]{2}{*}{$P(\mathrm{df}=1)$} \\
\hline & FB1 & FB2 & FB3 & FB4 & FB5 & Control & IA & & \\
\hline 16 & M & M & M & M & M & 0.545 & 0.527 & 0.242 & 0.623 \\
\hline 17 & $\mathrm{~m}$ & M & M & $\mathrm{m}$ & M & 0.152 & 0.144 & 0.048 & 0.827 \\
\hline 18 & M & M & M & $\mathrm{m}$ & M & 0.071 & 0.106 & 2.736 & 0.098 \\
\hline 19 & $\mathrm{~m}$ & M & M & M & M & 0.054 & 0.059 & 0.133 & 0.716 \\
\hline 20 & M & M & M & $\mathrm{m}$ & $\mathrm{m}$ & 0.082 & 0.055 & 1.828 & 0.176 \\
\hline
\end{tabular}

Table 5 Estimated haplotype frequencies calculated from SNPs in $L O X$ ( $M$ major allele, $m$ minor allele)

\begin{tabular}{|c|c|c|c|c|c|c|c|c|}
\hline \multirow[t]{2}{*}{ No. } & \multicolumn{4}{|c|}{ SNP name } & \multicolumn{2}{|c|}{ Frequency } & \multirow[b]{2}{*}{$\chi^{2}$} & \multirow[b]{2}{*}{$P(\mathrm{df}=1)$} \\
\hline & LO1 & $\mathrm{LO} 2$ & $\mathrm{LO} 3$ & LO4 & Control & IA & & \\
\hline 21 & M & M & M & M & 0.807 & 0.833 & 0.777 & 0.378 \\
\hline 22 & M & $\mathrm{m}$ & $\mathrm{m}$ & M & 0.117 & 0.087 & 1.570 & 0.210 \\
\hline 23 & $\mathrm{~m}$ & $\mathrm{~m}$ & M & $\mathrm{m}$ & 0.060 & 0.067 & 0.133 & 0.716 \\
\hline
\end{tabular}

\section{FGF1}

\begin{tabular}{|c|c|c|c|c|c|c|c|c|c|c|c|}
\hline \multirow{19}{*}{$\frac{\mathrm{SNP}}{\mathrm{FG1}}$} & FG1 & FG2 & FG3 & $\overline{F G}$ & & FG5 & FG6 & FG7 & FG8 & FG9 & FG10 \\
\hline & $\left|D^{\prime}\right|$ & $\overline{0.94}$ & 1.0 & & 69 & 0.029 & 0.068 & 0.202 & 0.017 & 0.111 & $\overline{0.112}$ \\
\hline & $r^{2}$ & 0.48 & 0.2 & & 26 & 0.001 & 0.001 & 0.020 & 0.000 & 0.003 & $\begin{array}{ll}30.009 \\
\end{array}$ \\
\hline & $\overline{F G 2}$ & $\left|D^{\prime}\right|$ & 1.0 & & 21 & 0.043 & 0.058 & 0.110 & 0.062 & 0.229 & 90.187 \\
\hline & & $r^{2}$ & 0.0 & & 000 & 0.001 & 0.001 & 0.003 & 0.001 & 0.003 & $\begin{array}{ll}30.026 \\
\end{array}$ \\
\hline & & $\overline{F G 3}$ & $\left|D^{\prime}\right|$ & & & 0.074 & 0.152 & 0.315 & 1.000 & 0.117 & 70.276 \\
\hline & & & & & 22 & 0.001 & 0.000 & 0.011 & 0.010 & 0.012 & 20.005 \\
\hline & & & $\overline{\mathrm{FG} 4}$ & $\mid D^{\prime}$ & & 0.254 & 0.001 & 0.069 & 1.000 & 0.701 & 10.056 \\
\hline & & & & & & 0.013 & 0.000 & 0.001 & 0.014 & +0.021 & 10.000 \\
\hline & & & & $\overline{F G}$ & & $\left|D^{\prime}\right|$ & 1.000 & 0.014 & 0.573 & 30.101 & 10.069 \\
\hline & & & & & & & 0.100 & 0.000 & 0.019 & 0.002 & 20.003 \\
\hline & & & & & & FG6 & $\left|D^{\prime}\right|$ & 0.296 & 1.000 & 1.000 & 0.260 \\
\hline & & & & & & & & 0.006 & 0.006 & 0.020 & 0.015 \\
\hline & & & & & & & $\overline{\text { FG7 }}$ & $\left|D^{\prime}\right|$ & 1.000 & 0.029 & 90.947 \\
\hline & & & & & & & & & 0.083 & 30.000 & 0.333 \\
\hline & & & & & & & & $\overline{\mathrm{FG} 8}$ & $\left|D^{\prime}\right|$ & 1.000 & 1.000 \\
\hline & & & & & & & & & & 0.308 & $\begin{array}{ll}80.031 \\
\end{array}$ \\
\hline & & & & & & & & & $\overline{\text { FG9 }}$ & $\left|D^{\prime}\right|$ & 1.000 \\
\hline & & & & & & & & & & & 0.087 \\
\hline
\end{tabular}

haplotypes were constructed with the three, two, and four SNPs in FGF1 according to the LD structure, no significant haplotype associations were observed (Table 3).

\section{Discussion}

The pathogenesis of IA is multifactorial, involving both genes and the environment. Many reports show the significance of the genetic component in the etiology of IA. Although the molecular determinants of IA are not clear, a six-base insertion allele in the endoglin gene and an insertion allele in the angiotensin-converting enzyme have been associated with increased risk of IA (Takenaka et al. 1999; Keramatipour et al. 2000). However, the association with the endoglin gene is not found in Caucasians (Krex et al. 2001), and we have not been able to replicate the association evidence in Japanese (Onda et al. 2003). Recently, we have reported a genome-wide

Fig. 2 Pairwise LD in $F G F 1, F B N 2$, and $L O X$, evaluated by $D^{\prime}$ and $r^{2}$. Pairwise LD among the 45, 10, and 6 marker pairs studied in $F G F 1, F B N 2$, and $L O X$ were computed, respectively, and pairs in LD $\left(\left|D^{\prime}\right|>0.5\right.$ or $\left.r^{2}>0.5\right)$ are shown as gray-shaded values

\section{FBN2}

\begin{tabular}{cccccc}
\hline SNP & FB1 & FB2 & FB3 & FB4 & FB5 \\
\hline FB1 & $\left|D^{\prime}\right|$ & 1.000 & 0.124 & 0.612 & 0.760 \\
& $r^{2}$ & 0.057 & 0.005 & 0.193 & 0.029 \\
\cline { 2 - 5 } & FB2 & $\left|D^{\prime}\right|$ & 0.655 & 1.000 & 1.000 \\
& & $r^{2}$ & 0.079 & 0.029 & 0.003 \\
\cline { 3 - 5 } & & FB3 & $\left|D^{\prime}\right|$ & 0.785 & 0.458 \\
& & & $r^{2}$ & 0.098 & 0.140 \\
\cline { 3 - 5 } & & & FB4 & $\left|D^{\prime}\right|$ & 0.958 \\
& & & & $r^{2}$ & 0.218 \\
\hline
\end{tabular}

LOX

\begin{tabular}{ccccc}
\hline SNP & LO1 & LO2 & LO3 & LO4 \\
\hline LO1 & $\left|D^{\prime}\right|$ & 1.000 & 0.046 & 0.904 \\
& $r^{2}$ & 0.285 & 0.001 & 0.661 \\
\cline { 2 - 5 } & LO2 & $\left|D^{\prime}\right|$ & 1.000 & 0.694 \\
& & $r^{2}$ & 0.600 & 0.168 \\
\cline { 3 - 5 } & & LO3 & $\left|D^{\prime}\right|$ & 0.320 \\
& & & $r^{2}$ & 0.001
\end{tabular}


linkage study of IA in 104 affected sib-pairs and revealed responsible genetic loci on chromosomes $5 \mathrm{q}, 7 \mathrm{q}$, and $14 \mathrm{q}$ (Onda et al. 2001). Although evidence of linkage for IA was found, performance of the positional cloning necessary to identify a causal gene was considered daunting, because the linkage regions in these loci spanned 10 $20 \mathrm{Mb}$. Accordingly, we used a candidate gene approach to investigate the involvement of the elastin gene (ELN) at a locus on chromosome 7. ELN lies close to the marker D7S2472, which showed the best evidence of linkage, and elastin constitutes the major component in vascular walls. A strong association between the intron 20/23 haplotype and IA was observed (Onda et al. 2001), but the functional implication of this haplotype association remains uncertain.

Evidence of linkage was also observed with D5S1983 on chromosome $5 \mathrm{q} 31$, where three candidate genes were identified: $F G F 1, F B N 2$, and $L O X$. The present study was designed to investigate whether the SNPs or haplotypes constructed with the SNPs in the three genes were associated with IA. Ten SNPs in FGF1, five in $F B N 2$, and four in $L O X$ were identified. Statistically significant association was observed only with the intron 4 SNP in FGF1 $(P=0.035$ in Table 2). Haplotype analysis can reveal the predisposition of a specific allele to a disease and is especially useful when the causal variant has not been identified. Haplotype 1 of $F G F 1$ shown in Table 3 was observed more frequently in IA patients than in controls indicating that the haplotype 1 constitutes an at-risk haplotype for IA among Japanese $(P=0.00006)$. However, when haplotypes were constructed with SNPs in LD within $F G F 1$, no strong associations with the haplotypes were observed (Table 3). A possible explanation for this discrepancy is that, because of multiple haplotypes obtained with ten SNPs, a false-positive association is observed. However, when the $P$-value was multiplied by the number of haplotypes (50 haplotypes represent $>0.3 \%$ of frequency) for correction, a positive association $(P=0.0031)$ could still be observed.

Fibroblast growth factor 1 is one of the fibroblast growth factor family members consisting of at least 23 structurally related polypeptides that play key roles in morphogenesis, development, angiogenesis, and wound healing (Burgess and Maciag 1989; Basilico and Moscatelli 1992; Naski and Ornitz 1998; ADHR Consortium 2000). Because fibroblast growth factor 1 promotes intimal hyperplasia and influences angiogenesis, it might well be involved in aneurysm formation (Burgess and Maciag 1989; Nabel et al. 1993; Skirgaudas et al. 1996). Although diseases associated with variations in $F G F 1$ have not been identified, missense mutations of FGF23 have been found in autosomal dominant hypophosphatemic rickets and represent the first example of a disease caused by the human FGF gene family (ADHR Consortium 2000). FGF1 contains alternative 5'untranslated exons, so the presence of at least four upstream untranslated exons spliced to the first coding exon should generate four distinct mRNAs (Myers et al. 1993). Although the functional role of haplotype 1 in the pathophysiology of IA is unclear, altered splicing is a possibility, since SNP FG8 occurs in intron 4, and $F G F 1$ exhibits alternative splicing. To clarify the role of $F G F 1$ in the etiology of IA, long-term functional analysis with all levels of biological technology is required.

The present results of the haplotype association indicate that the causal variant for IA may lie either within FGF1 or in a nearby gene; however, common variants associated with IA could not be determined. Although $L O X$ and FBN2 are also positional and functional candidate genes for IA, significant association of these genes with the development of IA could not be discerned.

Acknowledgements This work was supported in part by a Research for the Future Program Grant of the Japan Society for the Promotion of Science (to I. Inoue), Ministry of Public Health and Welfare Research on Human Genome, Tissue Engineering Food Biotechnology (to I. Inoue), a Grant-in-aid for Scientific Research (C) from the Japanese Ministry of Education, Science, Sports and Culture (to H. Kasuya), and Research Found of Mitsukoshi Health and Welfare Foundation 2002 (to H. Onda). We thank Yuka Terada for technical assistance.

\section{References}

ADHR Consortium (2000) Autosomal dominant hypophosphataemic rickets is associated with mutations in FGF23. Nat Genet 26:345-348

Baird A, Esch F, Mormede P, Ueno N, Ling N, Bohlen P, Ying SY, Wehrenberg WB, Guillemin R (1986) Molecular characterization of fibroblast growth factor: distribution and biological activities in various tissues. Recent Prog Horm Res 42:143-205

Basilico C, Moscatelli D (1992) The FGF family of growth factors and oncogenes. Adv Cancer Res 59:115-165

Burgess WH, Maciag T (1989) The heparin-binding (fibroblast) growth factor family of proteins. Annu Rev Biochem 58:575-606

Fogelholm R, Hernesniemi J, Vapalahti M (1993) Impact of early surgery on outcome after aneurysmal subarachnoid hemorrhage. A population-based study. Stroke 24:1649-1654

Gospodarowicz D, Neufeld G, Schweigerer L (1986) Molecular and biological characterization of fibroblast growth factor, an angiogenic factor which also controls the proliferation and differentiation of mesoderm and neuroectoderm derived cell. Cell Differ 19:1-17

Hill WG, Robertson A (1968) Linkage disequilibrium in finite populations. Theor Appl Genet 38:226-231

Inagawa T, Tokuda $\mathrm{Y}$, Ohbayashi $\mathrm{N}$, Takaya M, Moritake $\mathrm{K}$ (1995) Study of aneurysmal subarachnoid hemorrhage in Izumo City, Japan. Stroke 26:761-766

Ingall TJ, Whisnant JP, Wiebers DO, O'Fallon WM (1989) Has there been a decline in subarachnoid hemorrhage mortality? Stroke 20:718-724

Kagan HM, Trackman PC (1991) Properties and function of lysyl oxidase. Am J Respir Cell Mol Biol 5:206-210

Kagan HM, Vaccaro CA, Bronson RE, Tang SS, Brody JS (1986) Ultrastructural immunolocalization of lysyl oxidase in vascular connective tissue. J Cell Biol 103:1121-1128

Keramatipour M, McConnell RS, Kirkpatrick P, Tebbs S, Furlong RA, Rubinsztein DC (2000) The ACE I allele is associated with increased risk for ruptured intracranial aneurysms. J Med Genet 37:498-500

Kielty CM, Shuttleworth CA (1995) Fibrillin-containing microfibrils: structure and function in health and disease. Int $\mathrm{J}$ Biochem Cell Biol 27:747-760

Klagsbrun M, D'Amore PA (1991) Regulators of angiogenesis. Annu Rev Physiol 53:217-239 
Krex D, Ziegler A, Schackert HK, Schackert G (2001) Lack of association between endoglin intron 7 insertion polymorphism and intracranial aneurysms in a white population: evidence of racial/ethnicdifferences. Stroke 32:2689-2694

Lewontin RC (1964) The interaction of selection and linkage. I. General considerations; heterotic models. Genetics 49:49-67

Myers RL, Payson RA, Chotani MA, Deaven LL, Chiu IM (1993) Gene structure and differential expression of acidic fibroblast growth factor mRNA: identification and distribution of four different transcripts. Oncogene 8:341-349

Nabel EG, Yang ZY, Plautz G, Forough R, Zhan X, Haudenschild CC, Maciag T, Nabel GJ (1993) Recombinant fibroblast growth factor-1 promotes intimal hyperplasia and angiogenesis in arteries in vivo. Nature 362:844-846

Naski MC, Ornitz DM (1998) FGF signaling in skeletal development. Front Biosci 3:D781-D794

Onda H, Kasuya H, Yoneyama T, Takakura K, Hori T, Takeda J, Nakajima T, Inoue I (2001) Genomewide-linkage and haplotype-association studies map intracranial aneurysm to chromosome 7q11. Am J Hum Genet 69:804-819

Onda H, Kasuya H, Yoneyama T, Hori T, Nakajima T, Inoue I (2003) Endoglin is not a major susceptibility gene to intracranial aneurysms among Japanese. Stroke (in press)
Robinson PN, Godfrey M (2000) The molecular genetics of Marfan syndrome and related microfibrillopathies. J Med Genet 37:9-25

Ronkainen A, Hernesniemi J, Puranen M, Niemitukia L, Vanninen R, Ryynanen M, Kuivaniemi H, Tromp G (1997) Familial intracranial aneurysms. Lancet 349:380-384

Schievink WI, Schaid DJ, Michels VV, Piepgras DG (1995) Familial aneurysmal subarachnoid hemorrhage: a communitybased study. J Neurosurg 83:426-429

Skirgaudas M, Awad IA, Kim J, Rothbart D, Criscuolo G (1996) Expression of angiogenesis factors and selected vascular wall matrix proteins in intracranial saccular aneurysms. Neurosurgery 39:537-547

Takenaka K, Sakai H, Yamakawa H, Yoshimura S, Kumagai M, Yamakawa H, Nakashima S, Nozawa Y, Sakai N (1999) Polymorphism of the endoglin gene in patients with intracranial saccular aneurysms. J Neurosurg 90:935-938

Tsipouras P, Del Mastro R, Sarfarazi M, Lee B, Vitale E, Child AH, Godfrey M, Devereux RB, Hewett D, Steinmann B, et al (1992) Genetic linkage of the Marfan syndrome, ectopia lentis, and congenital contractural arachnodactyly to the fibrillin genes on chromosomes 15 and 5. N Engl J Med 326:905-909 